
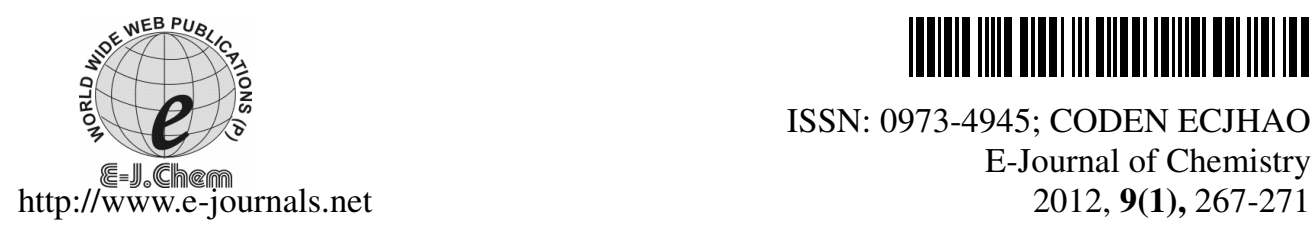

ISSN: 0973-4945; CODEN ECJHAO

E-Journal of Chemistry

2012, 9(1), 267-271

\title{
A Convenient and Efficient Protocol for the Synthesis of 1,3,5-Triaryl-2-pyrazolines in Acetic Acid under Ultrasound Irradiation
}

\author{
ZHI-PING LIN* and JI-TAI LI \\ *Department of Biology and Chemistry \\ Baoding University, Baoding -071000, P. R. China \\ College of Chemistry and Environmental Science \\ Hebei University, Baoding -071002, P. R. China \\ zhiping888999@yahoo.com.cn
}

Received 12 April 2011; Accepted 2 July 2011

\begin{abstract}
Triaryl-2-pyrazolines were synthesized in acetic acid in high yields within 60-180 min under ultrasound irradiation at room temperature.
\end{abstract}

Keywords: 1,3,5-Triaryl-2-pyrazolines, Acetic acid, Synthesis, Ultrasound irradiation

\section{Introduction}

Pyrazoline derivatives have been found to possess a broad spectrum of biological activities such as tranquillizing, muscle relaxant, psychoanaleptic, anticonvulsant, antihypertensive, and antidepressantactivities ${ }^{1-6}$. As a new type of highly active insecticide, pyrazolines had very high activity towards coleopteran and lepidopteran insects ${ }^{7}$. The results of preliminary bioassay indicated that some of the compounds showed fungicidal and plant growth regulatory activities ${ }^{8}$. Benzothiazole compounds with byrazoline group or benximidazole group are new fluorescent compounds. The fluorescent compounds have been used in many fields, but their development has been slow ${ }^{9,10}$. The results from Zhang group indicate that the fluorescence quantum yield of compound with methoxy group is higher than that of compound with the substituents of $N, N$-dimethlyamino group ${ }^{11}$.

Among of various pyrazoline derivatives, 2-pyrazolines seem to be the most frequently studied pyrazoline type compounds. A variety of methods have been reported for the preparation of this class of compounds. From $19^{\text {th }}$ century, the reaction of $\alpha$, $\beta$-unsaturated aldehydes and ketones with phenylhydrazine in acetic acid by refluxing became one of the most popular methods for the preparation of 2-pyrazolines ${ }^{12}$. Ultrasound has increasingly been used in organic synthesis in the last three decades. A large number of organic reactions can be carried out in higher yields, shorter reaction time or milder conditions under 
ultrasound irradiation. The preparation of 1,3,5-triaryl-2-pyrazolines has been reported ${ }^{13}$ in 2007 , but the reaction was occurred at high temperature. In this paper we wish to report an efficient and practical procedure for the synthesis of 1,3,5-triaryl-2-pyrazolines with chalcones and phenylhydrazine in acetic acid under ultrasound irradiation at room temperature (Scheme 1). In this protocol, acetic acid is the reaction solvent and also is the catalyst.

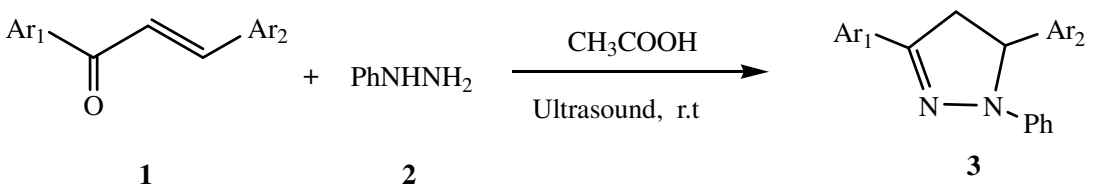

Scheme 1. Synthesis of 1,3,5-triaryl-2-pyrazolines under ultrasound irradiation

\section{Experimental}

Liquid substrates were distilled prior to use. Melting points were uncorrected. ${ }^{1} \mathrm{H}$ NMR spectra were recorded on a Bruker AVANCE $600(600 \mathrm{MHz})$ spectrometer using TMS as the internal standard and $\mathrm{CDCl}_{3}$ as solvent. Elemental analyses were measured on a HERAEUS (CHNO, Rapid) analyzer. Sonication was performed in Shanghai BUG40-06 or BUG25-06 ultrasonic cleaner (with a frequency of $25 \mathrm{kHz}, 40 \mathrm{kHz}, 59 \mathrm{kHz}$ and a nominal power $250 \mathrm{~W}$ ).

\section{Typical procedure for the preparation of 1,3,5-triaryl-2-pyrazolines}

The chalcones was prepared by the reported method ${ }^{14}$. Chalcones $(1,2 \mathrm{mmol})$ and phenylhydrazine $(2,6 \mathrm{mmol})$ were dissolved in acetic acid $(6 \mathrm{~mL})$ in a $50 \mathrm{~mL}$ conical flask. The mixture was irradiated in the water bath of an ultrasonic cleaner for the period as indicated in Table 2. The reaction mixture was poured into crushed ice. The precipitate was separated by filtration, washed with water, and crystallized from ethanol to obtain the 1,3,5-triaryl-2-pyrazolines. The authenticity of compounds were established by their ${ }^{1} \mathrm{H}$ NMR, elemental analysis data and melting point.

3a ${ }^{1} \mathrm{H}$ NMR (DMSO): $\delta 3.13(\mathrm{dd}, \mathrm{J}=7.2,17.2 \mathrm{~Hz}, 1 \mathrm{H}), 3.82(\mathrm{dd}, \mathrm{J}=12.4,16.8 \mathrm{~Hz}, 1 \mathrm{H}$ ), $5.26(\mathrm{dd}, \mathrm{J}=7.2,12 \mathrm{~Hz}, 1 \mathrm{H}) 6.80-7.75(\mathrm{~m}, 14 \mathrm{H}) \mathrm{ppm}$. Anal. calcd. for $\mathrm{C}_{21} \mathrm{H}_{18} \mathrm{~N}_{2}: \mathrm{C} 84.56, \mathrm{H}$ 6.04, N 9.39; found C 84.60, H 6.14, N 9.37.

3b: ${ }^{1} \mathrm{H}$ NMR (DMSO): $\delta 3.14(\mathrm{dd}, \mathrm{J}=7.2,17.2 \mathrm{~Hz}, 1 \mathrm{H}), 3.80\left(\mathrm{~s}, 3 \mathrm{H}, \mathrm{OCH}_{3}\right), 3.84$ (dd, J=12.4, 16.8 Hz, 1H), 5.26 (dd, J=7.2, $12 \mathrm{~Hz}, 1 \mathrm{H}) 6.80-7.75(\mathrm{~m}, 14 \mathrm{H}) \mathrm{ppm}$. Anal. calcd. for $\mathrm{C}_{22} \mathrm{H}_{20} \mathrm{~N}_{2} \mathrm{O}$ : C 80.48, H 6.09, N 8.54; found C 80.50, H 6.04, N 8.49.

3c: ${ }^{1} \mathrm{H}$ NMR (DMSO): $\delta 2.38\left(\mathrm{~s}, 3 \mathrm{H}, \mathrm{CH}_{3}\right), 3.15(\mathrm{dd}, \mathrm{J}=7.2,17.2 \mathrm{~Hz}, 1 \mathrm{H}), 3.85$ (dd, J=12.4, 17.2 Hz, 1H), 5.27 (dd, J=6.8, $12 \mathrm{~Hz}, 1 \mathrm{H}) 6.77-7.75(\mathrm{~m}, 14 \mathrm{H}) \mathrm{ppm}$. Anal. calcd. for $\mathrm{C}_{22} \mathrm{H}_{20} \mathrm{~N}_{2}$ : C 84.62, H 6.41, N 8.97; found C 84.61, H 6.43, N 9.00.

3d: ${ }^{1} \mathrm{H}$ NMR (DMSO): $\delta 3.09(\mathrm{dd}, \mathrm{J}=6.8,17.2 \mathrm{~Hz}, 1 \mathrm{H}), 3.40(\mathrm{dd}, \mathrm{J}=12.4,17.2 \mathrm{~Hz}, 1 \mathrm{H})$, $5.68(\mathrm{dd}, \mathrm{J}=6.8,12.4 \mathrm{~Hz}, 1 \mathrm{H}) 6.85-7.76(\mathrm{~m}, 14 \mathrm{H}) \mathrm{ppm}$. Anal. calcd. for $\mathrm{C}_{21} \mathrm{H}_{17} \mathrm{~N}_{2} \mathrm{Cl}$ : C 75.90, H 5.12, N 8.43; found C 75.83, H 5.23, N 8.45.

3e: ${ }^{1} \mathrm{H}$ NMR (DMSO): $\delta 3.08$ (dd, J=6.8, $\left.17.2 \mathrm{~Hz}, 1 \mathrm{H}\right), 3.40(\mathrm{dd}, \mathrm{J}=12.4,17.2 \mathrm{~Hz}, 1 \mathrm{H})$, $5.68(\mathrm{dd}, \mathrm{J}=6.8,12.4 \mathrm{~Hz}, 1 \mathrm{H}) 6.83-7.77(\mathrm{~m}, 14 \mathrm{H}) \mathrm{ppm}$. Anal. calcd. for $\mathrm{C}_{21} \mathrm{H}_{17} \mathrm{~N}_{2} \mathrm{Cl}$ : C 75.90, H 5.12, N 8.43; found C 75.93, H 5.13, N 8.45.

3f: ${ }^{1} \mathrm{H}$ NMR (DMSO): $\delta 3.08$ (dd, J=6.8, $\left.17.2 \mathrm{~Hz}, 1 \mathrm{H}\right), 3.40(\mathrm{dd}, \mathrm{J}=12.4,17.2 \mathrm{~Hz}, 1 \mathrm{H})$, $5.68(\mathrm{dd}, \mathrm{J}=6.8,12.4 \mathrm{~Hz}, 1 \mathrm{H}) 6.83-7.77(\mathrm{~m}, 14 \mathrm{H}) \mathrm{ppm}$. Anal. calcd. for $\mathrm{C}_{21} \mathrm{H}_{17} \mathrm{~N}_{2} \mathrm{Cl}$ : C 75.90, H 5.12, N 8.43; found C 75.93, H 5.14, N 8.44. 
3g: ${ }^{1} \mathrm{H}$ NMR (DMSO): $\delta 3.06$ (dd, J=6.8, $\left.17.1 \mathrm{~Hz}, 1 \mathrm{H}\right), 3.37(\mathrm{dd}, \mathrm{J}=12.4,17.2 \mathrm{~Hz}, 1 \mathrm{H})$, $5.65(\mathrm{dd}, \mathrm{J}=6.8,12.4 \mathrm{~Hz}, 1 \mathrm{H})$ 6.81-7.76 (m, $14 \mathrm{H}) \mathrm{ppm}$. Anal. calcd. for $\mathrm{C}_{21} \mathrm{H}_{17} \mathrm{~N}_{2}: \mathrm{C} 85.85$, H 5.72, N 9.43; found C 85.81, H 5.73, N 9.44.

3h: ${ }^{1} \mathrm{H}$ NMR (DMSO): $\delta 3.01(\mathrm{dd}, \mathrm{J}=7.8,16.8 \mathrm{~Hz}, 1 \mathrm{H}), 3.78\left(\mathrm{~s}, 3 \mathrm{H}, \mathrm{OCH}_{3}\right), 3.82$ (dd, J=12.4, $16.8 \mathrm{~Hz}, 1 \mathrm{H}), 3.84\left(\mathrm{~s}, 3 \mathrm{H}, \mathrm{OCH}_{3}\right), 5.26(\mathrm{dd}, \mathrm{J}=7.2,12 \mathrm{~Hz}, 1 \mathrm{H}) 6.80-7.75(\mathrm{~m}, 13 \mathrm{H})$ ppm. Anal. calcd. for $\mathrm{C}_{23} \mathrm{H}_{22} \mathrm{~N}_{2} \mathrm{O}_{2}$ : C 77.09, H 6.18, N 7.81; found C 76.69, H 6.14, N 7.70.

3i: ${ }^{1} \mathrm{H}$ NMR (DMSO): $\delta 3.15(\mathrm{dd}, \mathrm{J}=7.2,17.2 \mathrm{~Hz}, 1 \mathrm{H}), 3.80\left(\mathrm{~s}, 3 \mathrm{H}, \mathrm{OCH}_{3}\right), 3.84$ (dd, J=12.4, $16.8 \mathrm{~Hz}, 1 \mathrm{H}), 5.28(\mathrm{dd}, \mathrm{J}=7.2,12 \mathrm{~Hz}, 1 \mathrm{H}) 6.80-7.75(\mathrm{~m}, 13 \mathrm{H}) \mathrm{ppm}$. Anal. calcd. for $\mathrm{C}_{22} \mathrm{H}_{19} \mathrm{~N}_{2} \mathrm{OCl}$ : C 72.93, H 5.25, N 7.73; found C 71.50, H 5.34, N 7.49.

3j: ${ }^{1} \mathrm{H}$ NMR (DMSO): $\delta 3.14(\mathrm{dd}, \mathrm{J}=17.2,17.2 \mathrm{~Hz}, 1 \mathrm{H}), 3.84(\mathrm{dd}, \mathrm{J}=12.4,17.2 \mathrm{~Hz}, 1 \mathrm{H}$ ), $5.32(\mathrm{dd}, \mathrm{J}=7.6,12.4 \mathrm{~Hz}, 1 \mathrm{H}) 6.80-7.68(\mathrm{~m}, 14 \mathrm{H}) \mathrm{ppm}$. Anal. calcd. for $\mathrm{C}_{21} \mathrm{H}_{17} \mathrm{~N}_{2}: \mathrm{C} 84.85$, H 5.72, N 9.43; found C 84.87, H 5.74, N 9.46.

\section{Results and Discussion}

The effect of the reaction conditions on the reaction of chalcones and phenylhydrazine under ultrasound irradiation was summarized in Table 1. When the molar ratio of chalcones (1): phenylhydrazine (2) was 1:1, the yield of 1,3,5-triphenyl-2-pyrazoline was obtained in $88.1 \%$ yield (Table 1, Entry a). By increasing the molar ratio to $1: 1.5,1: 2$, and $1: 3$ the yields increased to $90.0,93.5$ and $95.6 \%$ respectively (Table 1, Entry b, c, d). The results showed that changing the molar ratio of 1:2 had a significant effect on the yield and the optimum molar ratio of chalcone: phenylhudrazine was 1:3. In the absence of ultrasound, the yield of 1,3,5-triphenyl-2-pyrazoline was only $77.0 \%$ (Entry l) by stirring at room temperature within $2 \mathrm{~h}$. The data of entry b, c, d, h and j in Table 2 also verify the effect of ultrasound. It is apparent that the reaction can be finished in a shorter time to give better yield under ultrasound.

Table 1. Effect of reaction condition on synthesis of 1,3,5-triphenyl-2-pyrazoline within $2 \mathrm{~h}$ under ultrasound

\begin{tabular}{ccccc}
\hline Entry & Molar ratio of $1: 2$ & Frequency, $\mathrm{kHz}$ & solvent & Isolated yield, $\%$ \\
\hline a & $1: 1.0$ & 25 & $\mathrm{HAc}$ & 88.1 \\
b & $1: 1.5$ & 25 & $\mathrm{HAc}$ & 90.0 \\
c & $1: 2.0$ & 25 & $\mathrm{HAc}$ & 93.5 \\
d & $1: 3.0$ & 25 & $\mathrm{HAc}$ & 95.6 \\
e & $1: 3.0$ & 40 & $\mathrm{HAc}$ & 94.6 \\
f & $1: 3.0$ & 59 & $\mathrm{HAc}$ & 92.6 \\
g & $1: 3.0$ & 25 & $\mathrm{EtOH}$ & 89.1 \\
h & $1: 3.0$ & 25 & $\mathrm{HAc}: \mathrm{H}_{2} \mathrm{O}=3: 1$ & 55.0 \\
i & $1: 3.0$ & 25 & $\mathrm{HAc}: \mathrm{H}_{2} \mathrm{O}=2: 2$ & 23.0 \\
j & $1: 3.0$ & 59 & $\mathrm{HAc}: \mathrm{H}_{2} \mathrm{O}=1: 3$ & trace \\
k & $1: 3.0$ & 25 & $\mathrm{H}_{2} \mathrm{O}$ & 0 \\
l & $1: 3.0$ & $\mathrm{Stir}^{\mathrm{a}}$ & $\mathrm{HAc}$ & 77.0 \\
\hline
\end{tabular}

${ }^{a}$ Stirred without ultrasound irradiation

When the frequency was $25 \mathrm{kHz}$, the reaction gave the desired product in $95.6 \%$ yield within $2 \mathrm{~h} \mathrm{~min}$ (Entry d). Under $40 \mathrm{kHz}$ and $59 \mathrm{kHz}$ ultrasound irradiation, the 1,3,5-triphenyl-2-pyrazoline was obtained with $94.6 \%$ and $92.6 \%$ yield respectively (Entry e and f), thus indicating that different frequency of ultrasound irradiation had no significant effect on the yield of 1,3,5-triphenyl-2-pyrazoline. 
We also carried out the reaction of chalcones and phenylhydrazine in acetic acid using different solvents under ultrasound. The results are listed in Table 1. The reaction in acetic acid proceeded smoothly under ultrasound irradiation, while not so efficient in the solvent including water. So the study continued to be done using acetic acid. And the most important in our protocol, no other catalyst need to add during the reaction. The acetic acid is the reaction solvent and also is the catalyst.

From the above results, the optimum reaction conditions were chosen; chalcone (1), $2 \mathrm{mmol}$, phenylhydrazine (2), $6 \mathrm{mmol}$ and acetic acid $6 \mathrm{~mL}$. Under this reaction system, a series of experiments for synthesis of 1,3,5-triaryl-2-pyrazolines under $25 \mathrm{kHz}$ ultrasound irradiation were performed. The results are summarized in Table 2.

Table 2. Synthesis of 1,3,5-triaryl-2-pyrazolines in acetic acid under ultrasounics at room temparature

\begin{tabular}{cccccc}
\hline Entry & $\mathrm{Ar}_{1}$ & $\mathrm{Ar}_{2}$ & Time, min & Yield, \% & m.p.Found(Lit.) ${ }^{\circ} \mathrm{C}[\mathrm{Ref}]$. \\
\hline $\mathrm{a}$ & $\mathrm{C}_{6} \mathrm{H}_{5}$ & $\mathrm{C}_{6} \mathrm{H}_{5}$ & 120 & 95.6 & $134-135(134-135)[6]$ \\
$\mathrm{b}$ & $\mathrm{C}_{6} \mathrm{H}_{5}$ & $4-\mathrm{CH}_{3} \mathrm{OC}_{6} \mathrm{H}_{4}$ & 110 & 99.0 & $110-111(110-112)[13]$ \\
& & & & $85.5^{\mathrm{a}}$ & - \\
$\mathrm{c}$ & $\mathrm{C}_{6} \mathrm{H}_{5}$ & $4-\mathrm{CH}_{3} \mathrm{C}_{6} \mathrm{H}_{4}$ & 90 & 99.0 & $127-129(128-130)[13]$ \\
& & & & $80.1^{\mathrm{a}}$ & - \\
$\mathrm{d}$ & $\mathrm{C}_{6} \mathrm{H}_{5}$ & $4-\mathrm{ClC}_{6} \mathrm{H}_{4}$ & 120 & 94.9 & $134-135(135-136)[13]$ \\
& & & & $79.8^{\mathrm{a}}$ & - \\
$\mathrm{e}$ & $\mathrm{C}_{6} \mathrm{H}_{5}$ & $3-\mathrm{ClC}_{6} \mathrm{H}_{4}$ & 100 & 87.8 & $134-135(134-136)[13]$ \\
$\mathrm{f}$ & $\mathrm{C}_{6} \mathrm{H}_{5}$ & $2-\mathrm{ClC}_{6} \mathrm{H}_{4}$ & 100 & 84.9 & $134-135(135-136)[13]$ \\
$\mathrm{g}$ & $\mathrm{C}_{6} \mathrm{H}_{5}$ & $3-\mathrm{BrC}_{6} \mathrm{H}_{4}$ & 180 & 18.3 & $141-142(141-143)[13]$ \\
$\mathrm{h}$ & $4-\mathrm{CH}_{3} \mathrm{OC}_{6} \mathrm{H}_{4}$ & $4-\mathrm{CH}_{3} \mathrm{OC}_{6} \mathrm{H}_{4}$ & 60 & 97.9 & $139-141(139-140)[15]$ \\
& & & & $81.3^{\mathrm{a}}$ & - \\
$\mathrm{i}$ & $4-\mathrm{ClC}_{6} \mathrm{H}_{4}$ & $4-\mathrm{CH}_{3} \mathrm{OC}_{6} \mathrm{H}_{4}$ & 60 & 95.5 & $158-159(160-161)[16]$ \\
$\mathrm{j}$ & $4-\mathrm{ClC}_{6} \mathrm{H}_{4}$ & $\mathrm{C}_{6} \mathrm{H}_{5}$ & 90 & 89.5 & $142-144(143-145)[13]$ \\
& & & & $75.9^{\mathrm{a}}$ & - \\
k & $\mathrm{C}_{6} \mathrm{H}_{5}$ & $4-\mathrm{NO}_{2} \mathrm{C}_{6} \mathrm{H}_{4}$ & 180 & trace & - \\
\hline
\end{tabular}

${ }^{a}$ The reaction was occurred without ultrasound

From the Table 2 data, it seems that either electron-donating substituents or electronwithdrawing substituents in the benzene ring have no significant effects on the yields in this system. 1,3-Diphenyl-5-(4-methylphenyl)-2-pyrazoline and 1,3-diphenyl-5-(4-chlorophenyl) -2-pyrazoline can obtain in $88 \%$ and $86 \%$ yield as per literature report, but it is higher to $99.0 \%$ and $94.9 \%$ in present system at room temperature. Moreover, acetic acid both is the reaction solvent, and is the catalyst.

In conclusion, we have found an efficient and practical procedure for the synthesis of some 1,3,5-triaryl-2-pyrazolines via the condensation of chalcones and phenylhydrazine under ultrasound irradiation at room temperature.

\section{Acknowledgment}

The project was supported by Natural Science Foundation of Hebei Province (B2006000969), China. 


\section{References}

1. Patel V M and Desai K R, Arkivoc, 2004, (i), 123.

2. Chen Y, Lam Y L and Lai Y H, Org Lett., 2003, 5, 1067.

3. Parmar S S, Pandey B R, Dwivedi C and Harbinson R D, J Pharm Sci., 1974, 63, 1152.

4. Soni N, Pande K, Kalsi R, Gupta T K, Parmar S S and Barthwal J P, Res Commun Chem Pathol Pharm., 1987, 56(1), 129-132.

5. Turan-Zitouni G, Chevallet P, Kilic F S and Erol K, Eur J Med Chem., 2000, 35(6), 635-641.

6. Rajendra Y P, Lakshmana R A, Prasoona K, Murali K and Ravi K P, Bioorg Med Chem Lett., 2005, 15, 5030-5034.

7. Salgado V L, Pesti Sci., 1990, 28, 389.

8. Franck-Neumann M and Miesch M, Tetrahedron Lett, 1982, 23, 1409.

9. Jin M, Lu Ran, Chuai X H, Zhang Y H and Zhao Y Y, Chem J Chin Univ., 2002, 23, 466.

10. Zhu W H and Tian H, Prog Chem., 2002, 14, 18.

11. Zhang X H, Wu S K, Gao Z Q, Li Z S and Li S T, Acta Chimica Sinaca, 2000, 58, 293.

12. Levai A, ARKIVOC, 2005, (ix), 344 .

13. Li J T, Zhang X H and Lin Z P, Beilstein J Org Chem., 2007, 3, 13.

14. Li J T, Yang W Z, Wang S X, Li S H and Li T S, Ultrason Sonochem., 2002, 9, 237-239.

15. Ando W, Sato R, Yamashita M, Akasaka T and Miyazaki H, J Org Chem., 1983, 48, 542 .

16. Kidwai M, Kukreja S and Thakur R, Lett Org Chem., 2006, 3, 135. 


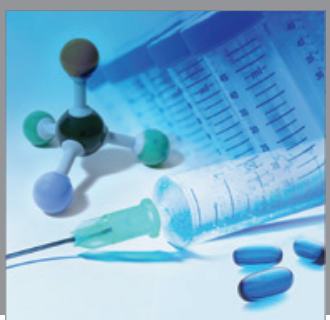

International Journal of

Medicinal Chemistry

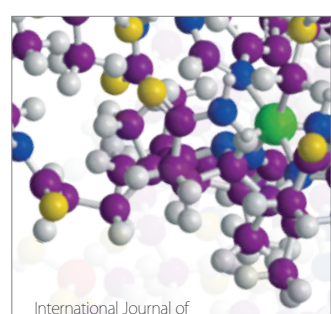

Carbohydrate Chemistry

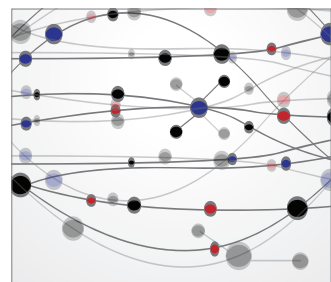

The Scientific World Journal
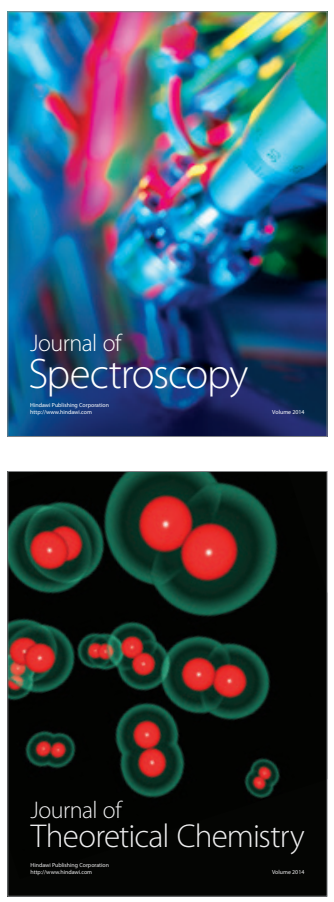
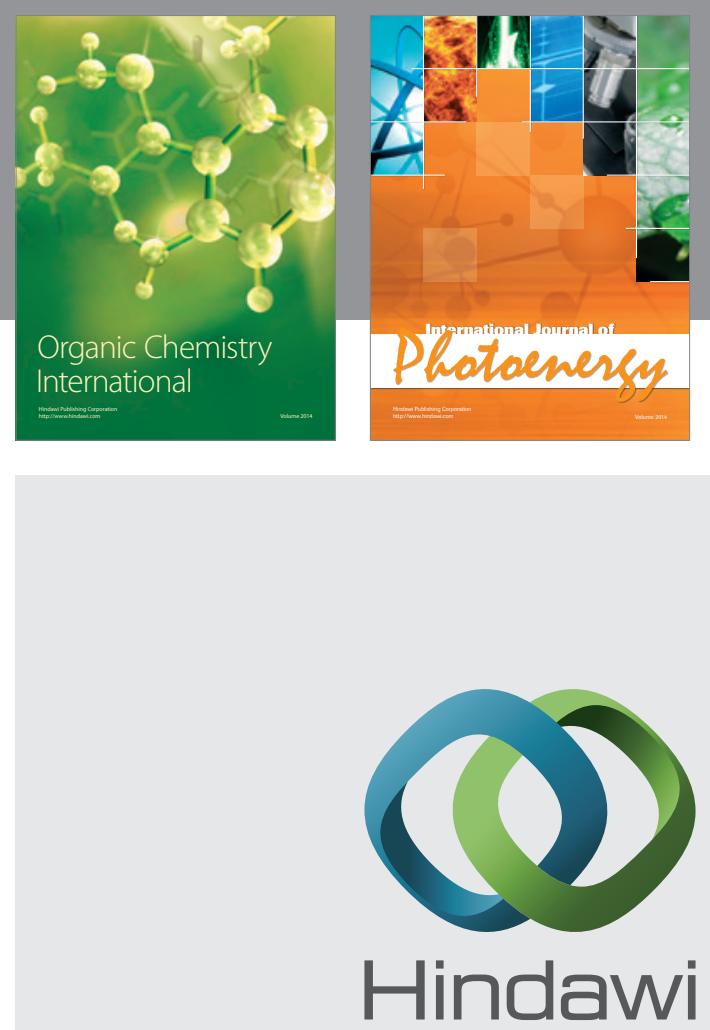

Submit your manuscripts at

http://www.hindawi.com
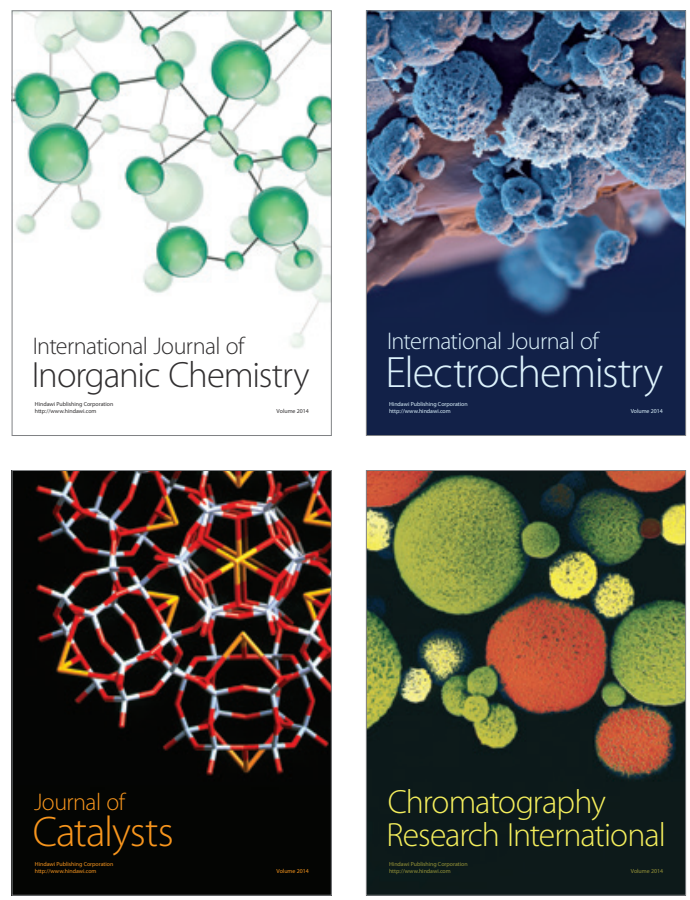
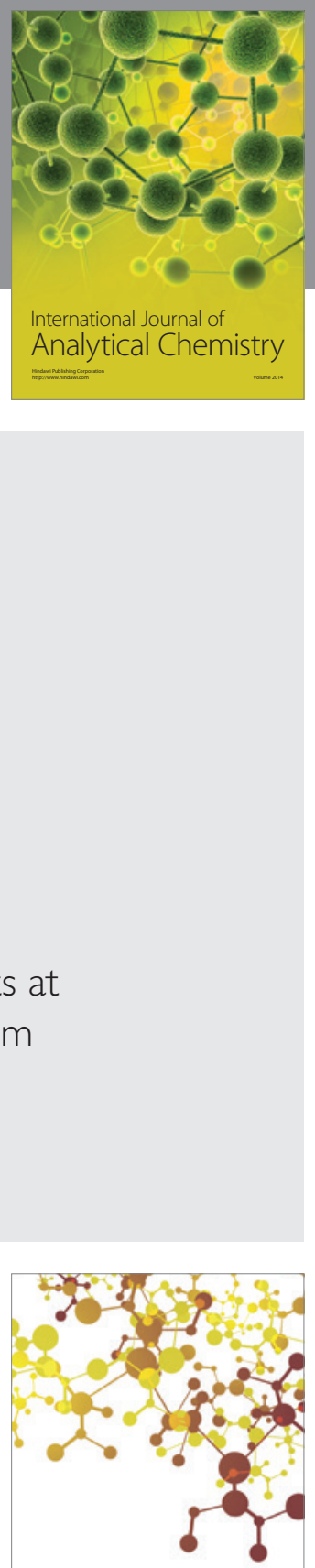

Journal of

Applied Chemistry
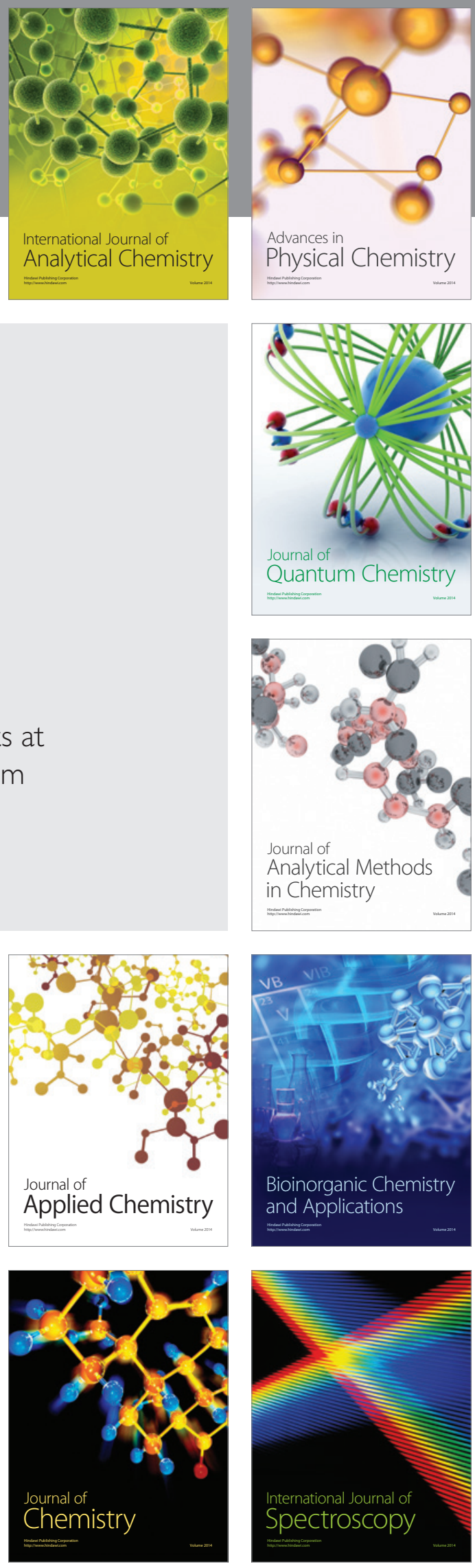